\title{
Velocity Bias Induced by Flow Patterns around ADCPs and Associated Deployment Platforms
}

\author{
David S. Mueller \\ U.S. Geological Survey \\ Office of Surface Water \\ Louisville, KY 40299 \\ dmueller@usgs.gov
}

\begin{abstract}
Velocity measurements near the Acoustic Doppler Current Profiler (ADCP) are important for mapping surface currents, measuring velocity and discharge in shallow streams, and providing accurate estimates of discharge in the top unmeasured portion of the water column. Improvements to ADCP performance permit measurement of velocities much closer $(5 \mathrm{~cm})$ to the transducer than has been possible in the past $(25 \mathrm{~cm})$. Velocity profiles collected by the U.S. Geological Survey (USGS) with a $1200 \mathrm{kHz}$ Rio Grande Zedhead ADCP in 2002 showed a negative bias in measured velocities near the transducers. On the basis of these results, the USGS initiated a study combining field, laboratory, and numerical modeling data to assess the effect of flow patterns caused by flow around the ADCP and deployment platforms on velocities measured near the transducers. This ongoing study has shown that the negative bias observed in the field is due to the flow pattern around the ADCP. The flow pattern around an ADCP violates the basic assumption of flow homogeneity required for an accurate three-dimensional velocity solution. Results, to date (2014), have indicated velocity biases within the measurable profile, due to flow disturbance, for the TRDI $1200 \mathrm{kHz}$ Rio Grande Zedhead and the SonTek RiverSurveyor M9 ADCPs. The flow speed past the ADCP, the mount and the deployment platform have also been shown to play an important role in the magnitude and extent of the velocity bias.
\end{abstract}

Keywords-Acoustic Doppler Current Profiler (ADCP), computational fluid dynamics, hydrodynamics, field data, modeling

\section{INTRODUCTION}

The use of acoustic Doppler current profilers (ADCPs) for making discharge and water velocity measurements in streams and rivers has increased dramatically as manufacturers have refined the acoustic technique for use in depths as shallow as $0.5 \mathrm{~m}$. In 2013, the U. S. Geological Survey (USGS) Water Mission Area made over 16,000 measurements of discharge using ADCPs. In addition, ease of use and spatial and temporal detail of measured velocities have made the ADCP a commonly used tool for mapping velocity fields that are used to assess aquatic habitat and validate numerical models [1, 2, 3].

The blanking distance (blank) from the transducers required before valid data can be obtained was one of the issues limiting the minimum depth for ADCP measurements. Blanking distance is the distance (time) the emitted sound travels while internal electronics prepare for data reception and the transducers stop vibrating from the transmission and become quiescent enough to accurately record the backscattered acoustic energy. Improvements in transducer design have reduced this blanking distance to as little as $3 \mathrm{~cm}$. This blanking distance only accounts for the transducer characteristics and does not consider the flow field that develops around an ADCP and whether the velocities measured near the ADCP are representative of the undisturbed streamflow. This paper presents field data and numerical simulations for different instruments deployed in various ways that show measured velocities within the flow field that develops around an ADCP are biased low.

\section{INTITIAL INVESTIGATION}

Gartner and Ganju [4] observed distortion in velocity profiles measured by a stationary downward-looking Teledyne RD Instruments (TRDI) Rio Grande ${ }^{1}$ ADCP in the San Joaquin River at Vernalis, California, and the Delta Mendota Canal at Byron, California. Initial tests in the San Joaquin River at Vernalis, California, showed velocity magnitudes measured by the ADCP in the upper three or four bins were less than those measured by a SonTek acoustic Doppler velocimeter $(\mathrm{ADV})$ mounted near the ADCP. The bins closest to the transducer had the largest negative bias (10 to $15 \%$ ). Subsequent measurements were made on the Delta Mendota Canal at Bryon, California, to evaluate the effect of varying the blanking distance (between 5 and $25 \mathrm{~cm}$ ) on the measured velocity profile. The Delta Mendota Canal is a man-made concrete (trapezoidal) channel approximately $30 \mathrm{~m}$ wide at the surface and about $5 \mathrm{~m}$ deep. During the tests, the water speed was nearly constant $(+/-$ about $1.5 \%)$ through the range of depths (about 30-130 cm) sampled by the ADV. ADCP- and ADV-measured velocities compared favorably below about 70 $\mathrm{cm}$ from the water surface, indicating that the difference in sample volumes between instruments had a negligible effect on the observed biases. Although the aspect ratio of the channel was 5:1, no evidence suggesting secondary circulation that would cause maximum velocities below surface was found within $130 \mathrm{~cm}$ of the surface. The 1,200 kilohertz $(\mathrm{kHz})$

${ }^{1}$ Note: Any use of trade, product, or firm names is for descriptive purposes only and does not imply endorsement by the U.S. Government. 
ADCP was configured for water mode $5,5 \mathrm{~cm}$ bins, and an immersion depth of $21.5 \mathrm{~cm}$. The use of water mode 5 in this depth of water with a $1,200 \mathrm{kHz}$ ADCP resulted in only the top half of the velocity profile being measured. ADCP (single ping) measurements spanned at least 205 seconds to correspond with the ADV samples. For each set of measurements, the ADV was positioned on a bridge across the canal in the middle of a long and straight section about $1.5 \mathrm{~m}$ from the ADCP and at a depth corresponding to the center of bin 1 of the ADCP. The ADV was programmed to sample at $10 \mathrm{~Hz}$ using $100 \mathrm{~cm} / \mathrm{s}$ velocity scale for 2048 samples. Similar to previous results at Vernalis, portions of velocity profiles near surface were biased low (Fig. 1).

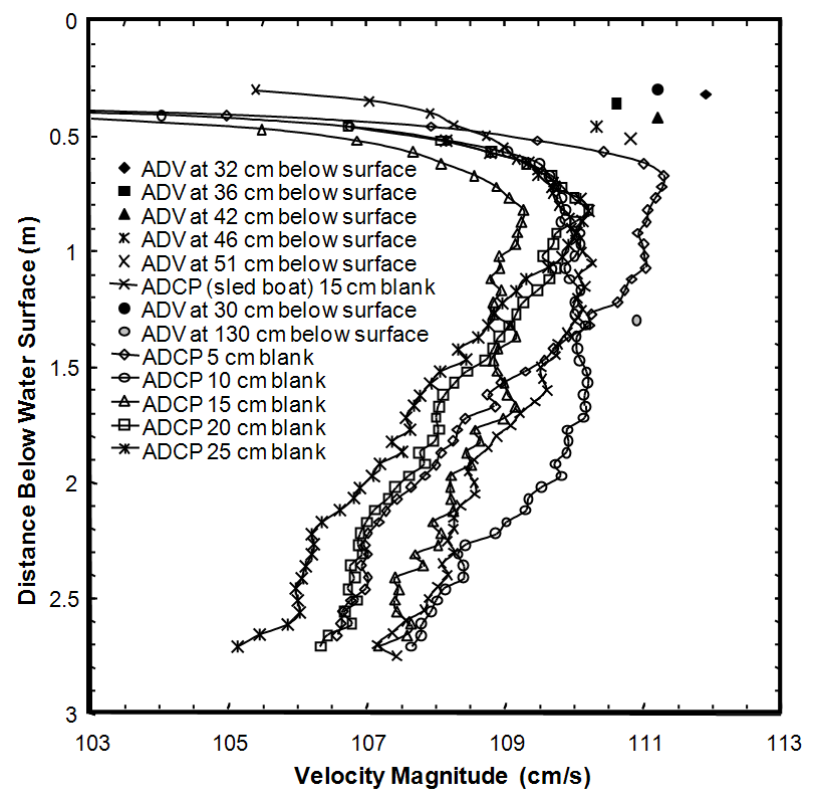

Fig. 1. ADCP velocity profiles and ADV point velocity measurements in Delta Mendota Canal at Bryon, California, on January 24, 2002.

The USGS [5] investigated the velocity bias reported by Gartner and Ganju [4] through the use of commercially available computational fluid dynamics model (CFD), Flow3D [6]. The unbiased portion of the profile data from the Delta Mendota Canal was used to develop a logarithmic velocity profile that was used for the upstream boundary of the model. The ADCP and mount used for deployment were defined as obstructions in the model. The model was then used to simulate the flow field around the ADCP. In order to compare the simulated velocities with the field observations, the velocity that the ADCP would have measured from the simulated flow field had to be computed.

The velocity that would have been measured by the ADCP was computed from the simulation results. The location of the path of each beam was mapped into the computational mesh. Velocity data from the specific beam location were used to compute the simulated beam velocity. Beam velocities were computed by converting the $\mathrm{u}, \mathrm{v}$, and $\mathrm{w}$ velocity components for each beam to the velocity component parallel to the beam. Using a standard transformation matrix [7], the beam velocities were converted to $\mathrm{u}, \mathrm{v}$, and $\mathrm{w}$ velocity components that would be measured by the ADCP in the simulated flow field. Finally, the velocity profile was averaged into bins matching the configuration of the ADCP using the weighted averaging procedure applied in the ADCP [8].

The ADCP velocity profile computed from the simulated flow field compared closely with the mean of the ADCP velocity profiles observed by [4]. A simulated ADCP profile is plotted in Fig. 2a together with the five observed velocity profiles from the Delta Mendota Canal collected on January 24, 2002, and the mean of those five profiles. The CFD model simulation produced results with mean differences between the simulated and field profile of $0.1 \%$ with a coefficient of variation of $0.2 \%$ and a maximum deviation from the observed data at any point in the profile of $1 \%$. The surface distortion in the simulations also replicates that observed in the field (Fig. 2b).

Comparison of the field data reported by [4] and the numerical simulations of those data confirm the hypothesis that velocities measured close to an ADCP not only violate the flow homogeneity assumption, but have magnitudes that are contrary to expected velocities near a flow obstruction [5]. Subsequently, the USGS recommended a $25 \mathrm{~cm}$ blank for all Rio Grande ADCP configurations [9]. The work presented in [5] also supports use of the numerical model to study the effects of the deployment configuration, immersion depth of

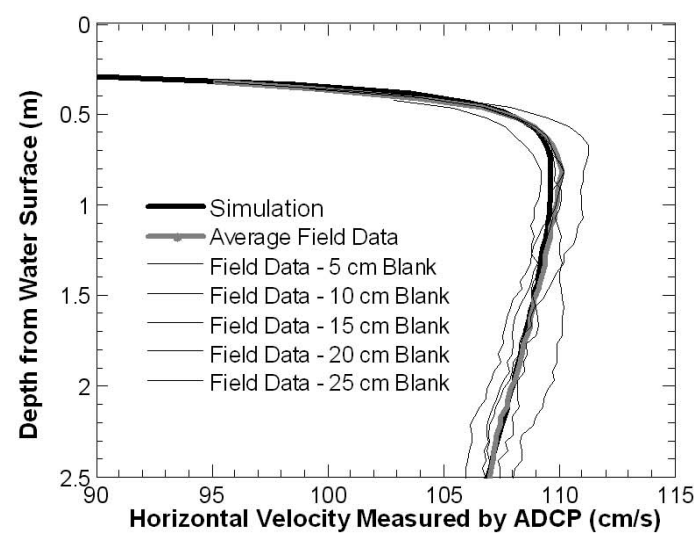

a) Horizontal Velocity Comparison

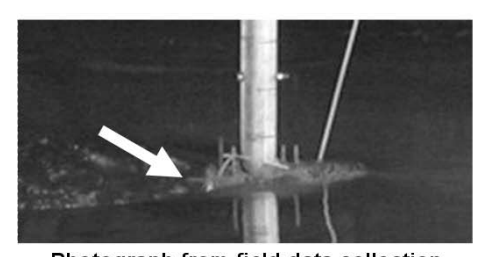

Photograph from field data collection

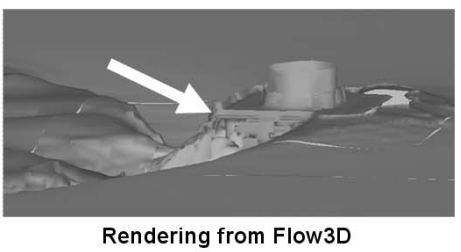

b) Visual Comparison of Free Surface

Fig. 2. Comparison of simulated and observed ADCP measured velocity profiles (a) and qualitative comparison of free surface between photograph during data collection and rendering of modeled free surface (b). 
the instrument, and streamflow conditions on the flow disturbance and resulting ADCP velocity measurements.

\section{EVALUATION OF ADDITIONAL CONFIGURATIONS}

The USGS uses several different types of ADCPs and deploys them using different tethered boats, in addition to manned boats. Evaluation of the effects of flow disturbance on the velocities measured near the transducer using the approach described by [5] has been completed on the TRDI Rio Grande, StreamPro, RiverRay, and SonTek RiverSurveyor ADCPs. In addition, the changes in the flow field caused by deploying these instruments in the OceanScience Riverboat and SonTek hydroboard tethered boats have been evaluated.

\section{A. Rio Grande and Riverboat}

The flow simulations of the Rio Grande ADCP were completed for deployments using a simple pipe mount as might be used on a manned boat (the manned boat was not simulated) and the Riverboat. These simulations were analyzed to represent both water mode 5 and water mode 1 configurations of the Rio Grande. For a 1,200 kHz Rio Grande the minimum cells size would be $5 \mathrm{~cm}$ for water mode 5 and $25 \mathrm{~cm}$ for water mode 1 . Figure 3 shows the results of two different pipe mount deployments with drafts (transducer
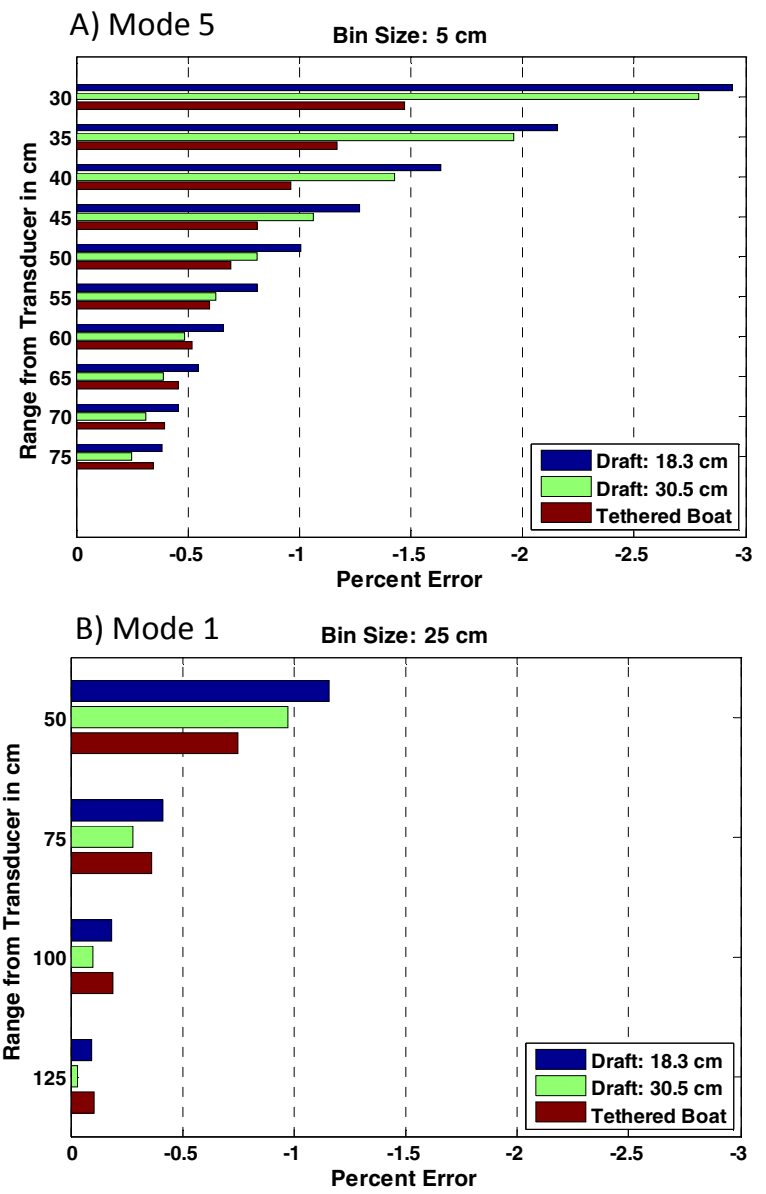

Fig. 3. Percent bias in measured velocity for the Rio Grande operating in A) Mode 5 and B) Mode 1 for different deployments. depth below the water surface) of 18.3 and $30.5 \mathrm{~cm}$ and deployment in the OceanScience Riverboat employing the USGS recommended $25 \mathrm{~cm}$ blank for a relative velocity of 61 $\mathrm{cm} / \mathrm{s}$. The deployment in a Riverboat results in less bias in the top three cells than a deployment where the ADCP is completely exposed to the flow.

\section{B. StreamPro}

The StreamPro ADCP has a smaller diameter than the Rio Grande and is designed for use in shallow water [10]. TRDI provides a tethered float with the StreamPro, which has two deployment options: 1) ADCP deployed off the front and 2)
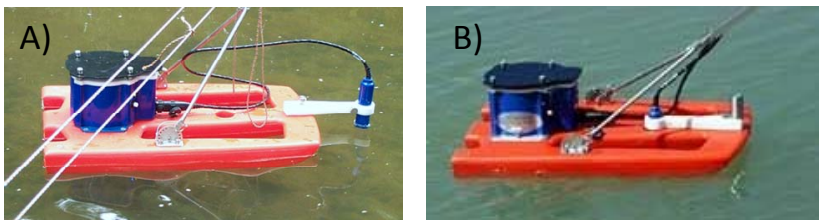

Fig. 4. Photographs of the TRDI StreamPro deployed off the front (A) and through the hull (B) of the TRDI float.

ADCP deployed through the hull (Fig. 4). Simulations with the StreamPro only and with the StreamPro deployed through the hull of the provided float showed a significant difference in the velocity field around the ADCP (Fig. 5). The effect of the flow field on the measured velocities was actually greater with the StreamPro only than when it was deployed through the hull of the provided float. Using the smallest blank of $3 \mathrm{~cm}$ and the smallest bin size of $2 \mathrm{~cm}$, the results of simulations of the StreamPro deployed through the hull of the float with downstream velocities ranging from 0.3 to $91 \mathrm{~cm} / \mathrm{s}$ showed that the bias in the measured velocity was nearly always less than $1 \%$ (Fig. 6). The blank and bin sizes were small enough that the top two bins measured the velocity acceleration as flow passed beneath the ADCP and float. This measured acceleration is due to the small size of the ADCP beam pattern relative to the flow patterns show in Fig. $5 \mathrm{~A}$ and $\mathrm{B}$.

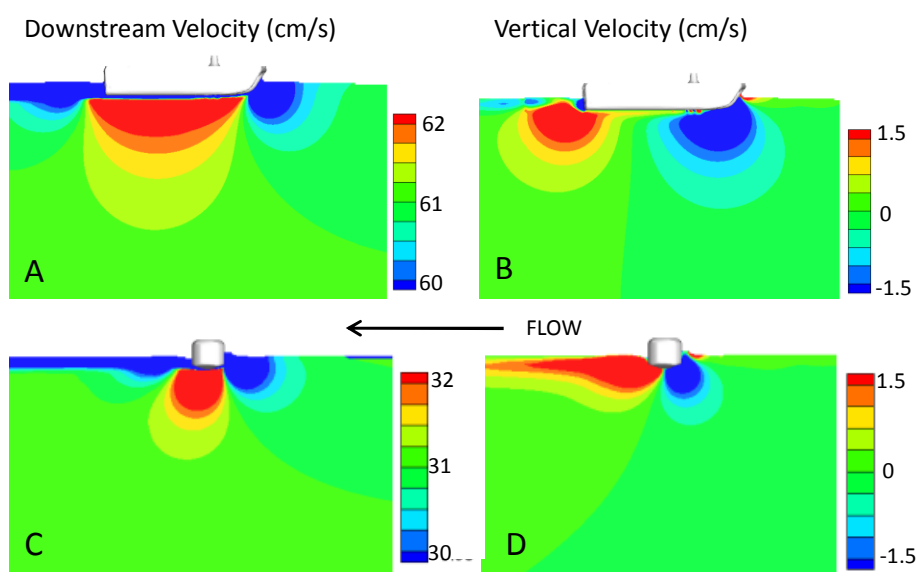

Fig. 5. Detailed color contour of downstream and vertical velocities for StreamPro simulations with $(61 \mathrm{~cm} / \mathrm{s})$ and without $(31 \mathrm{~cm} / \mathrm{s})$ the float. 


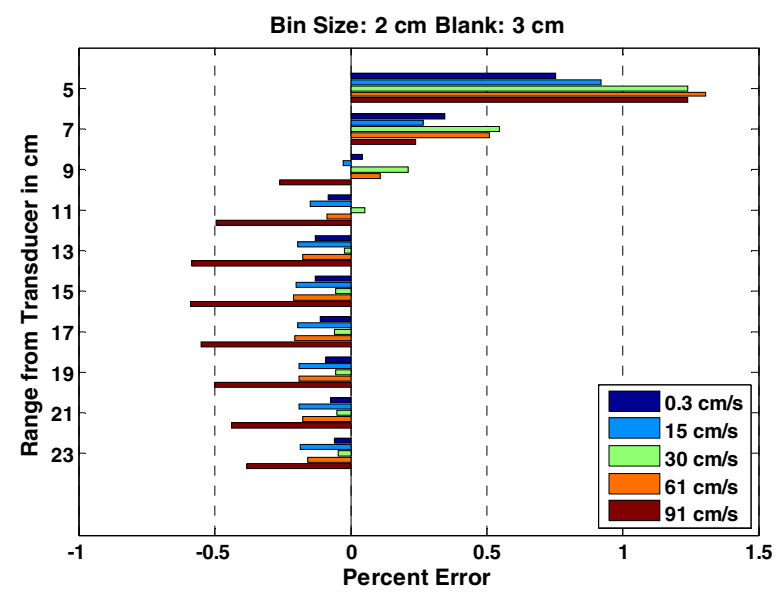

Fig. 6. Bias in measured velocity for the StreamPro deployed through the hull of the float simulated at various velocities.

\section{RiverRay}

The TRDI RiverRay ADCP is designed with a phasedarray transducer. One of the advantages of the phased-array transducer is that it allows the transducer face of the ADCP to be flat (Fig. 7A) as opposed to the convex shape required by ADCPs designed with piston transducers. TRDI also provides a tethered boat as standard equipment with the RiverRay (Fig. 7B).
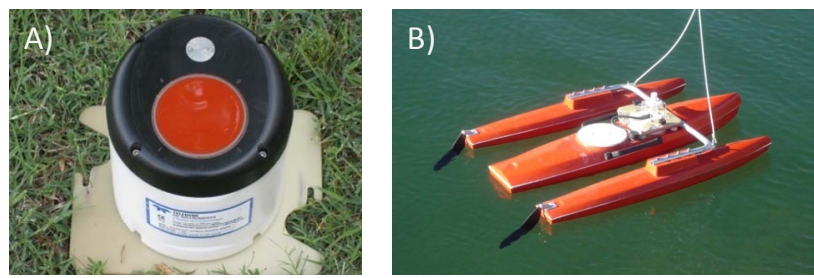

Fig. 7. Photographs of (A) the RiverRay showing the flat phased-array transducer and (B) the RiverRay deployed in the TRDI tethered boat.

Simulations were completed for the RiverRay deployed from a pipe mount and in the provided tethered boat for velocities ranging from 15 to $244 \mathrm{~cm} / \mathrm{s}$. The smallest bin size for the RiverRay is $10 \mathrm{~cm}$ [11]. In the standard auto-adaptive operational mode, the RiverRay adjusts the blanking distance so that the range to the center of the first depth cell is always $25 \mathrm{~cm}$ from the transducer [9]. The bias in the velocity the ADCP would have measured in a $10 \mathrm{~cm}$ bin centered $25 \mathrm{~cm}$ from the transducer was evaluated. The design of the RiverRay and provided tethered boat resulted in a significant improvement in velocity bias when compared to the pipe mounted RiverRay (Fig. 8). When deployed from a pipe mount the velocity bias was $1 \%$ or less but when deployed from the provided tethered boat the velocity bias was less than about $0.4 \%$ for the conditions simulated. The manufacturer specification for blanking distance and bin size is sufficient to avoid measuring velocities that are biased substantially by the flow field around the ADCP and/or tethered boat.

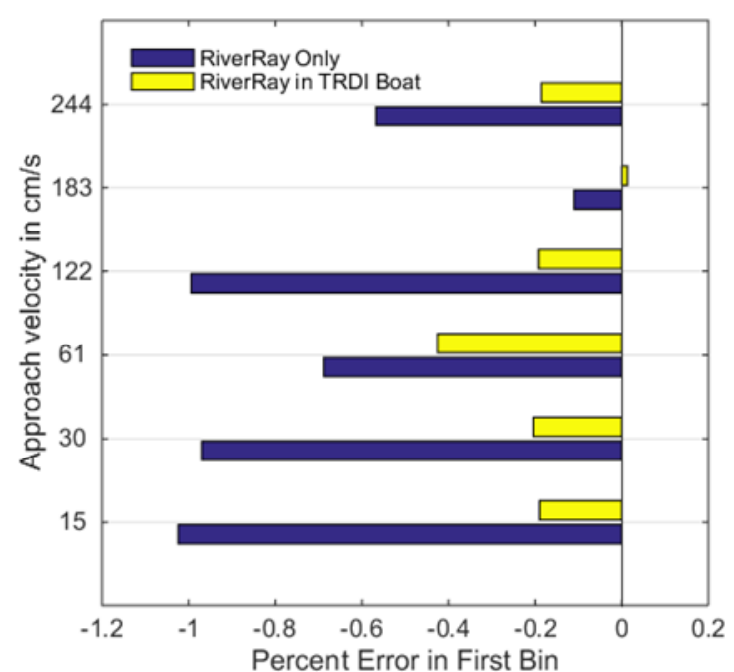

Fig. 8. Percent error in the first $10-\mathrm{cm}$ bin centered $25 \mathrm{~cm}$ below the RiverRay.

\section{RiverSurveyor $M 9$}

The RiverSurveyor M9 is a multi-frequency ADCP consisting of 4 beams operating at $1 \mathrm{MHz}, 4$ beams operating at $3 \mathrm{MHz}$, and a vertical beam operating at $500 \mathrm{kHz}$ [12]. Three different configurations of the RiverSurveyor M9 have been evaluated: 1) M9 only, 2) M9 in a small hydroboard, and 3) M9 in a large hydroboard (Fig 9). Each of these configurations was simulated using a uniform infinite flow field with no bottom or side boundary effects. The simulations were completed at the following approach velocities: 15,30 , $61,122,183$, and $244 \mathrm{~cm} / \mathrm{s}$. An example of the distribution of the downstream velocity around the small hydroboard with the M9 deployed for 61 and $183 \mathrm{~cm} / \mathrm{s}$ approach velocities is shown in Fig. 10. The interaction of the flow field caused by the hydroboard with the flow field caused by the ADCP protruding from the bottom of the hydroboard varies with flow velocity.

The effect of flow disturbance is most evident when the M9 is operating in $3 \mathrm{MHz}$ HD mode because the blanking distance and depth cell size are small resulting in velocity

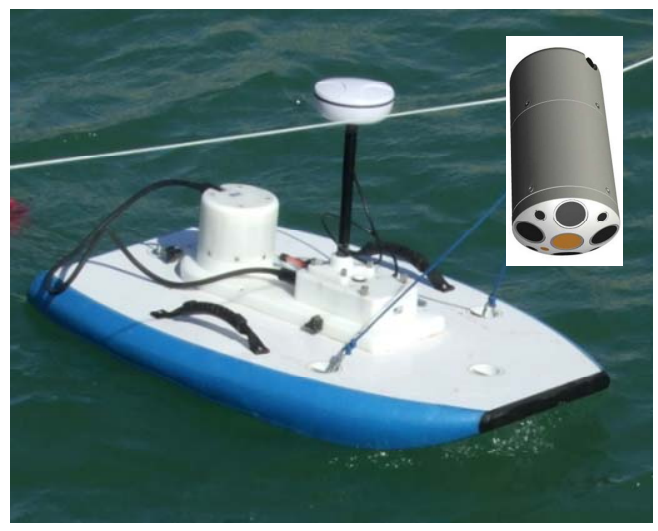

Fig. 9. Photograph of the RiverSurveyor M9 (inset) deployed in the small SonTek hydroboard. 

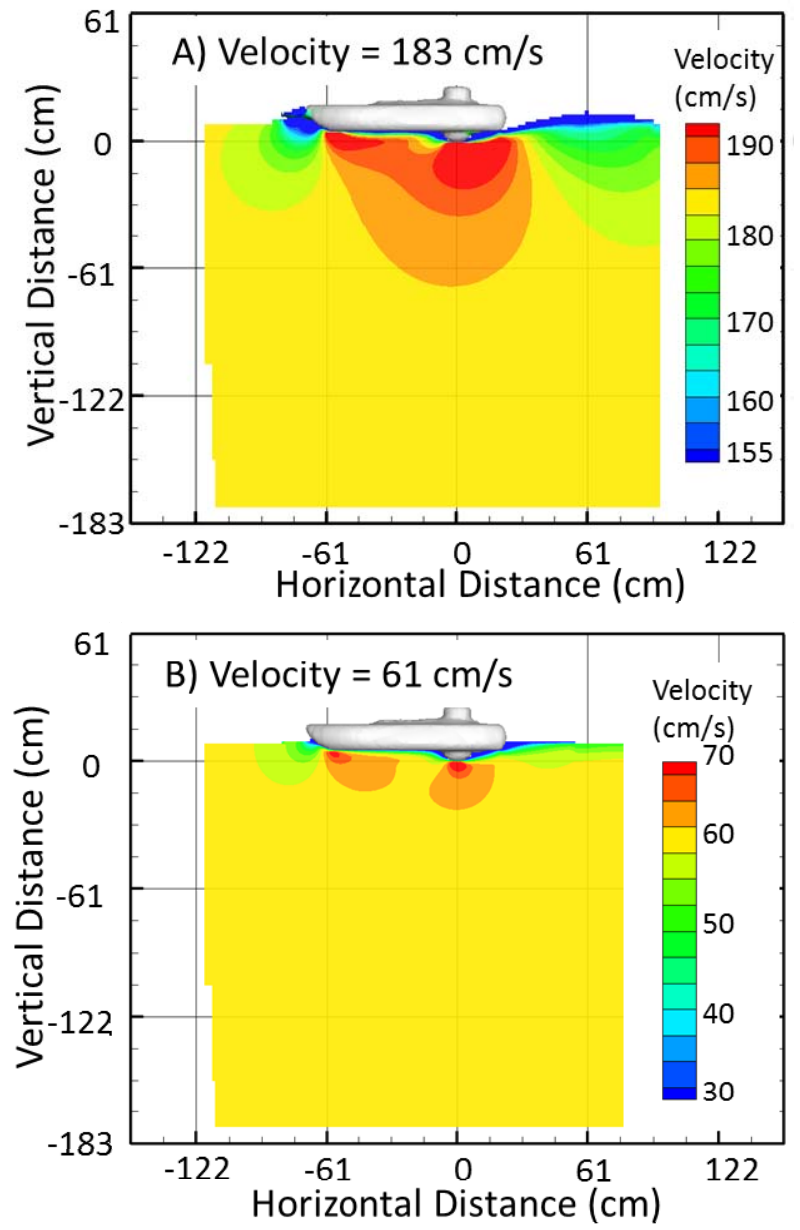

Fig 10. Example of difference in the downstream flow field for simulations of the small hydroboard at approach velocities of A) 183 and B) $61 \mathrm{~cm} / \mathrm{s}$. Vertical distance referenced to bottom of transducer.

measurements very close to the transducers (within about 7 $\mathrm{cm}$ ). The percent error of the simulated ADCP measured velocity compared with the approach velocity for the $3 \mathrm{MHz}$ HD mode is shown in Fig. 11. For some velocities and configurations, the effect of the flow disturbance is reduced to less than $1 \%$ at about $13 \mathrm{~cm}$ from the transducer while for the mean or median of all the simulations, the effect of flow disturbance is not reduced to less than $1 \%$ until about $22 \mathrm{~cm}$ from the transducer. Thus, the effect of the flow disturbance could bias the velocities measured near the transducer when the M9 is operated in the $3 \mathrm{MHz} \mathrm{HD}$ mode with default values for blanking distance and bin size.

Because numerical simulations and discharge measurement review indicated the possibility of flow disturbance producing a low bias in M9 discharge measurements within the manufacturer specified sampling distance from the transducer, three special sets of data were collected with an M9 and a StreamPro to validate the numerical model results. The StreamPro was chosen for comparison because field experience and numerical modeling (presented herein) did not indicate flow disturbance within the measurement range, and the range and vertical resolution were
$3 \mathrm{MHz}, 5 \mathrm{~cm}$ blank, $2 \mathrm{~cm}$ bins

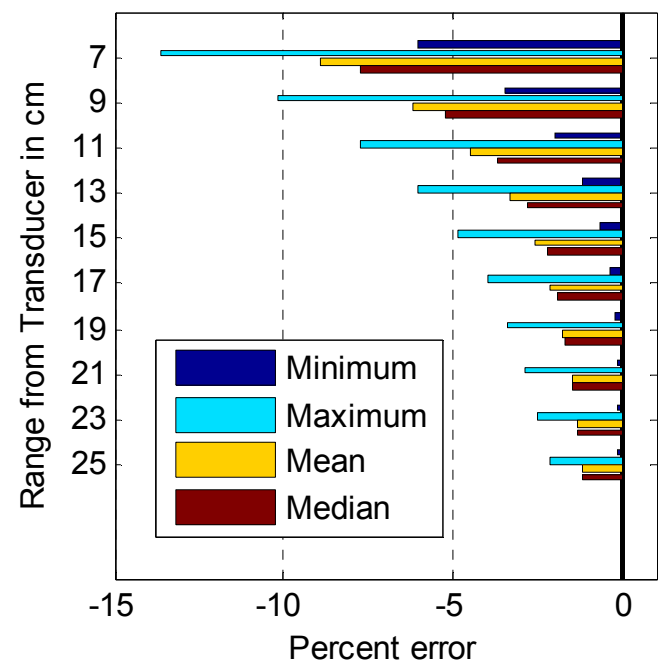

Fig. 11. Summary of simulations for the RiverSurveyor M9 with blanking distance and depth cell size associated with the 3 MHz HD mode.

most similar to that of the M9. For each data set, sequential stationary profiles were collected in the same location within the cross section. Data were processed outside the manufacturer's software to obtain mean velocity profiles. The results of all three tests were similar to the data shown in Fig. 12.

The numerical simulations of the M9 in the large hydroboard using a uniform flow field and no influence of a bottom boundary and approach velocities of 61 and $122 \mathrm{~cm} / \mathrm{s}$ indicated a $1 \%$ or greater error in the velocity profile due to flow disturbance to a distance of about $19 \mathrm{~cm}$. The difference between the infinite flow field simulations and the field data is likely due to a constriction of the velocity profile caused by the flume bottom and a flow depth of less than $0.6 \mathrm{~m}$. To validate that the source of the difference between the prior numerical simulations and field data was in fact due to the solid boundary and shallow flow depth, an additional simulation was completed using the M9 deployed in the large hydroboard and the geometry of the Lower Colorado River Authority Plant No. 2 flume as solid boundaries. The result of this numerical simulation (Fig. 13) shows close agreement in the shape of the simulated profile with the measured profiles and validates the inflection point of the profile at $15 \mathrm{~cm}$.

The bend back in the velocity profile caused by flow disturbance will bias the measured discharge low in two ways:

1) the measured portion of the profile affected by the bend back will result in a low bias of the computed discharge for this portion of the cross section; and

2) the bend back will lead to the selection of an incorrect profile extrapolation method and result in the extrapolated discharge being biased low.

From field data and model simulations, the location of the bend back was $15 \mathrm{~cm}$ from the transducer for a flow depth of approximately $0.6 \mathrm{~m}$ and up to $22 \mathrm{~cm}$ for infinite flow depths. 


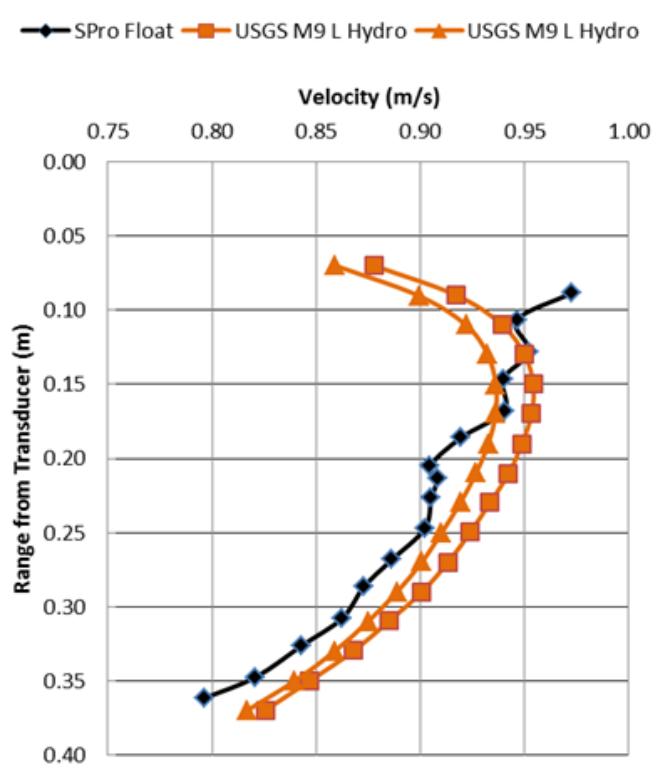

Fig. 12. Comparison of average velocity profiles for M9 in large hydroboard to StreamPro in float provided with the instrument for data collected in the Lower Colorado River Authority Plant No. 2 flume.

The maximum range of the $3 \mathrm{MHz} \mathrm{HD}$ mode from the M9 is $1.5 \mathrm{~m}$. This analysis of the potential effect of the velocity profile bias on discharge will assume the bend back begins 14 $\mathrm{cm}$ from the transducer for a flow depth of $0.4 \mathrm{~m}$ and $20 \mathrm{~cm}$ from the transducer for the maximum flow depth of $1.5 \mathrm{~m}$. A $10-\mathrm{cm}$ draft with the center of the first $2-\mathrm{cm}$ cell located $7 \mathrm{~cm}$ from the transducer and a power velocity profile with an exponent of 0.1667 will represent a typical deployment for a 3 $\mathrm{MHz}$ Pulse Coherent mode application. Given these parameters, the effect of the biased velocity profile on the measured discharge varies from about $6 \%$ at a flow depth of $0.4 \mathrm{~m}$ to about $1.3 \%$ for flow depths near $1.5 \mathrm{~m}$.

Currently the RiverSurveyor M9 uses the following blanking distances:

$1 \mathrm{MHz}$ Incoherent: $10 \mathrm{~cm}$

$1 \mathrm{MHz}$ Pulse Coherent: $16 \mathrm{~cm}$

$3 \mathrm{MHz}$ Incoherent: $5 \mathrm{~cm}$

\section{$3 \mathrm{MHz}$ Pulse Coherent: $5 \mathrm{~cm}$}

If the bias is in the top $15-20 \mathrm{~cm}$ of the $3 \mathrm{MHz}$ profile, it is also in the $1 \mathrm{MHz}$ data. Model simulations for the $1 \mathrm{MHz}$ beams indicate that flow disturbance causes a $1 \%$ or greater bias in the measured velocities to a range of about $20 \mathrm{~cm}$. This is often not seen in field data because the large cell size averages across the bias and unbiased portions of the profiles. The bias is more readily seen in the $3 \mathrm{MHz}$ pulse coherent mode because the blank and cell sizes are small. The use of the $1 \mathrm{MHz}$ Pulse Coherent blanking distance of $16 \mathrm{~cm}$ for all modes would reduce the small hidden bias in the $1 \mathrm{MHz}$ data and the observed bias in the $3 \mathrm{MHz}$ data. Using the assumptions of the analysis of percent error in discharge discussed previously and assuming that any time the bend back occurs (even slightly for $1 \mathrm{~cm}$ ) a constant extrapolation is

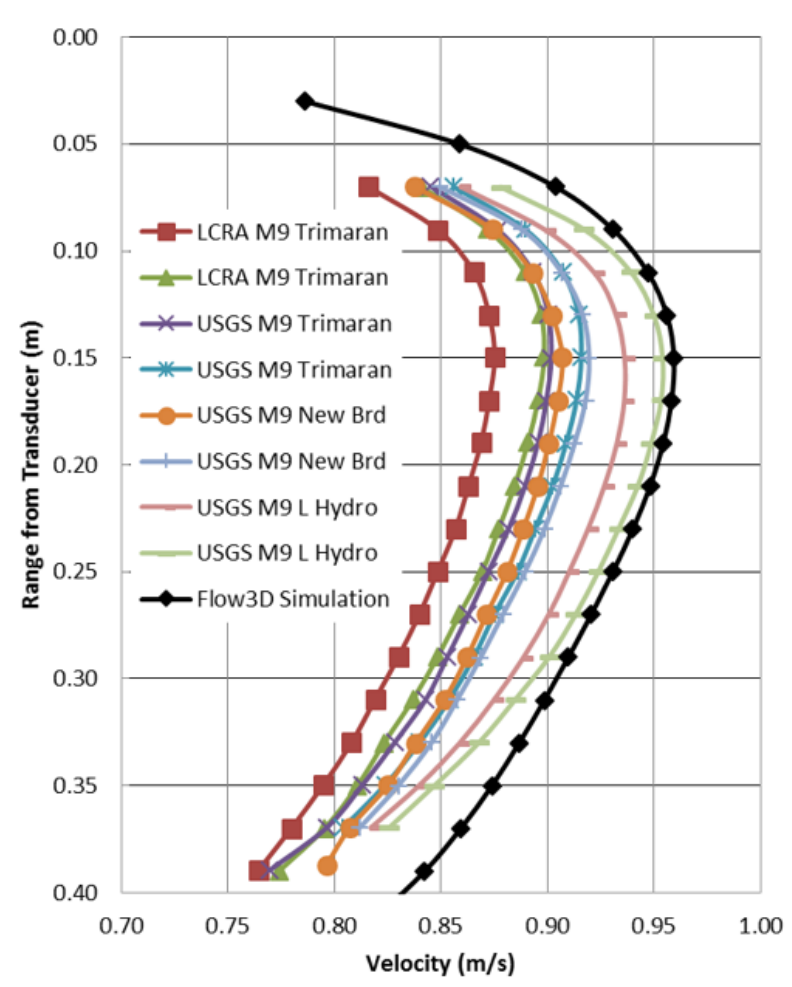

Fig. 13. Comparison of numerical simulation results with velocity profiles measured using the SonTek RiverSurveyor M9 for the Lower Colorado River Authority Plant No. 2 flume.

used reduces the discharge bias to less than $1.5 \%$. This is the worst case, as typically several depth cells with a prevalent bend back would be required to select a constant extrapolation. Thus, the use of a constant blanking distance of $16 \mathrm{~cm}$, which is the default for the $1 \mathrm{MHz}$ Pulse Coherent mode, would provide more reliable data for all operating frequencies and modes of the RiverSurveyor M9.

\section{SUMMARY AND CONCLUSIONS}

Improvements to ADCP and transducer performance permit measurement of velocities much closer $(5 \mathrm{~cm})$ to the transducer than has been possible in the past $(25 \mathrm{~cm})$. Field observations with some ADCPs showed a trend for a low bias in velocities near the transducers. Additional field investigations suggested that this low bias near the transducers was due to the disturbed flow field around the ADCP. A commercial computational fluid dynamics model was used to simulate the flow around four different ADCPs deployed in various configurations. Simulation results indicated two ADCPs - the Teledyne RD Instruments Rio Grande 1,200 $\mathrm{kHz}$ ZedHead and the SonTek RiverSurveyor M9 — would allow data to be collected near the transducers that were bias low by more than $1 \%$. In both situations field data were collected that confirmed the model results. The current policies of the USGS Water Mission Area specify a minimum range to the top of the first bin of $25 \mathrm{~cm}$ for the Rio Grande and $16 \mathrm{~cm}$ for the RiverSurveyor M9 [9]. The flow speed past the ADCP, the mount, and the deployment platform were also 
shown to play an important role in the magnitude and extent of the velocity bias. Data collected with an ADCP near the transducer should consider the flow field that develops around the ADCP and associated deployment platform. Ignoring the effects of the ADCP and associated deployment platform could result in measured velocities with a negative bias.

\section{REFERENCES}

[1] D. R. Parsons, P. R. Jackson, J. A. Czuba, F. L. Engel, B. L. Rhoads, K. A. Oberg, J. L. Best, D. S. Mueller, K. K. Johnson, and J. D. Riley, "Velocity Mapping Toolbox (VMT): a processing and visualization suite for moving-vessel ADCP measurements," Earth Surface Processes and Landforms, Volume 38, Issue 11, pp. 1244-1260, September 2013.

[2] R. B. Jacobson, C. M. Elliott, and H. E. Johnson III, “Assessment of shallow-water habitat availability in modified dike structures, lower Missouri River," U.S. Geological Survey Open-File Report 2004-1409, 2004.

[3] C. R. Wagner and D. S. Mueller, "Calibration and validation of a twodimensional hydrodynamic model of the Ohio River, Jefferson County, Kentucky,” U.S. Geological Survey Water-Resources Investigations Report 01-4091, 2001.

[4] J. W. Gartner, and N. K. Ganju, (2002). "A preliminary evaluation of near-transducer velocities collected with low-blank acoustic Doppler current profiler," Proc. of Hydraulic Measurements and Experimental Methods (CD-ROM), 2002.

[5] D. S. Mueller, J. D. Abad, C. M. García, J. W. Gartner, M. H. García, and K. A. Oberg, "Errors in acoustic Doppler profiler velocity measurements caused by flow disturbance," ASCE J. Hyd. Eng., v. 133 , no. 12, pp. 1411-1420, 2007.

[6] Flow Science, Inc., Flow-3d v. 9.0 User Manual. Flow Science, Inc., Santa Fe, NM, 2005.

[7] RD Instruments, "ADCP coordinate transformation booklet: Teledyne RD Instruments.”, $<$ http://www.rdinstruments.com/x/cs/documents.html $>$ (Mar. 31, 2006).

[8] RD Instruments, Principles of Operation: A Practical Primer - Second Edition for Broadband ADCPs. RD Instruments, San Diego, CA, 1996.

[9] D. S. Mueller, C. R. Wagner, M. S. Rehmel, K. A. Oberg, and Francois Rainville, "Measuring discharge with acoustic Doppler current profilers from a moving boat (ver. 2.0, December 2013)," U.S. Geological Survey Techniques and Methods, book 3, chap. A22, 95 p., 2013.

[10] Teledyne RD Instruments, StreamPro ADCP Operation Manual. Teledyne RD Instruments, San Diego, CA., P/N 95B-6003-00, 2008.

[11] Teledyne RD Instruments, RiverRay ADCP Guide. Teledyne RD Instruments, San Diego, CA, P/N 95B-6063-00, 2013

[12] SonTek/YSI, RiverSurveyor S5/M9 System Manual - Firmware Version 3.00. SonTek/YSI, San Diego, CA, 2012. 